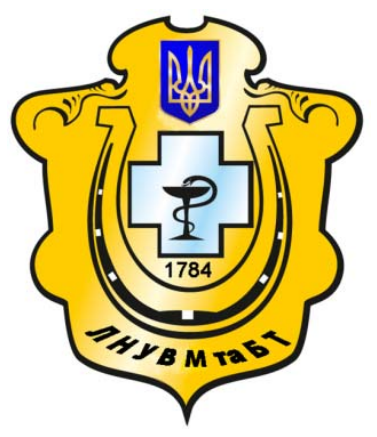

Науковий вісник Львівського національного університету ветеринарної медицини та біотехнологій імені С.З. Гжицького

Scientific Messenger of Lviv National University of Veterinary Medicine and Biotechnologies named after S.Z. Gzhytskyj

doi:10.15421/nvlvet7502

ISSN 2519-268X print

ISSN 2518-1327 online

$\underline{\text { http://nvlvet.com.ua/ }}$

УДК 664.002.5(075)

\title{
Вплив поверхнево-активних речовин на поверхневий критерій в ламінарному приграничному шарі
}

\author{
Ю.Л. Білонога ${ }^{1}$ О.Р. Максисько ${ }^{1}$ І.Г. Свідрак² \\ yuriy_bilonoha@ukr.net \\ ${ }^{I}$ Львівський національний університет ветеринарної медицини та біотехнологій імені С.3. Гюсицького, \\ вул. Пекарська, 50, м. Львів, 79010, Украӥна; \\ 2 Львівський національний університет «Львівська політехніка» \\ вул. Степана Бандери, 12, Львів, 79013, Украӥна;
}

\begin{abstract}
Показано, щзо на межі потік теплоносія - стінка трубопроводу, тобто в межах ламінарного приграничного шару (ЛПШ), виникає потужне поле сил поверхневого натягу. Інтенсивність поверхневих сил характеризується поверхневим критерієм. Експериментально знайдено значення коефічієнта поверхневого натягу $\sigma$, косинуса кута змочування сов $\theta$ та динамічного коефічієнта в'язкості $\mu$ водних розчинів під впливом поверхнево-активних речовин (ПАР). До водних розчинів додавались найбільш потирені аніонна, неіонна та катіонна ПАР. Визначені оптимальні концентрації ичих ПАР до «льодяної» води. Встановлено, що за оптимальних конщентрацій ПАР значення поверхневого натягу є мінімальним. Обчислено середню товщину ламінарного приграничного шару за додавання до води оптимальних конщентраиій досліджуваних ПАР. Встановлено, щуо зменшення коефіцієнта поверхневого натягу мінімізує товщини ЛПШ у системі стінка трубопроводувода. Показано, щуо середня швидкість в пристінних шарах за додавання оптимальних концентрацій досліджуваних ПАР зростає, $і$ як наслідок така система здатна ефективніше передавати кількість тепла. Визначено числові діапазони поверхневого критерію для «льодяної» води за додавання різного виду ПАР.

Ключові слова: ламінарний приграничний шар, середня товщина приграничного ламінарного шару, поверхневий натяг, поверхнево-активні речовини, швидкість в ламінарному приграничному шарі, оптимальні концентрації, поверхневий критерій.
\end{abstract}

\section{Влияние поверхностно-активных веществ на поверхностный критерий в ламинарном пограничном слое}

\author{
Ю.Л. Билонога ${ }^{1}$, О.Р. Максысько ${ }^{1}$ І.Г. Свидрак² \\ yuriy_bilonoha@ukr.net
}

\footnotetext{
${ }^{1}$ Львовский национальный университет ветеринарной медицины и биотехнологий имени С.3. Гжицкого, ул. Пекарская, 50, г. Львов, 79010, Украина;

2 Львовский национальный университет «Львовская политехника», ул. Степана Бандеры, 12, Львов, 79013, Украина;
}

Показано, что на границе поток теплоносителя - стенка трубопровода, то есть в пределах ламинарного пограничного слоя (ЛПШ), возникает мощное поле сил поверхностного натяжения. Интенсивность поверхностных сил характеризуется поверхностным критерием. Экспериментально найдено значение коэффициента поверхностного натяжения, косинуса угла смачивания и динамического коэффичиента вязкости водных растворов под влиянием поверхностно-активных веществ (ПАВ). К водным растворам добавлялись наиболее распространенные анионная, неионная та катионная ПАВ. Определены оптимальные концентрации этих ПАВ к «ледяной» воде. Установлено, что при оптимальных концентраций ПАВ значение поверхностного натяжения является минимальным. Вычислено среднюю толщину ЛПШ за добавление к воде оптимальных концентраций исследуемых ПАВ. Установлено, что уменьшение коэффициента поверхностного натя-

\section{Citation:}

Bilonoha, Y.L., Maksysko, O.R., Svidrak, I.G. (2017). Effect of surfactants on surface criteria in laminar boundary layer. Scientific Messenger LNUVMBT named after S.Z. Gzhytskyj, 19(75), 8-12. 
жения минимизирует толшины ЛПШ в системе стенка трубопровода-вода. Показано, что средняя скорость в пристенных слоях за добавление оптимальных концентраций исследуемых ПАВ растет, и как следствие такая система способна эффективно передавать количество тепла. Определены числовые диапазоны поверхностного критерия для «ледяной» воды с добавление различного вида ПАВ.

Ключевые слова: ламинарный пограничный слой, средняя толщцна пограничного ламинарного слоя, поверхностное натяжение, поверхностно-активные вещества, скорость в ламинарном пограничном слое, оптимальнье концентрации, поверхностный критерий.

\title{
Effect of surfactants on surface criteria in laminar boundary layer
}

\author{
Y.L. Bilonoha ${ }^{1}$, O.R. Maksysko' ${ }^{1}$, I.G. Svidrak ${ }^{2}$ \\ yuriy_bilonoha@ukr.net \\ ${ }^{1}$ Lviv national university of veterinary medicine and biotechnologies named after S. Gzhytskyj, \\ Pekarska Str., 50, Lviv, 79010, Ukraine; \\ ${ }^{2}$ Lviv National Polytechnic University «Lviv Polytechnic», \\ Stepan Bandera Str., 12, Lviv 79013, Ukraine;
}

It is shown that on the border the flow of the coolant - wall pipe, that is, within the laminar boundary layer (LBL), there is a powerful field of forces of surface tension. The intensity of surface forces characterized by superficial criteria $P_{o}$ The value surface of the criterion Reynolds and Euler's criterion in LBL several orders of magnitude more from the Froude criterion and inverse of the Reynolds criterion, so the latter can be neglected. Experimentally found value of surface tension, cosine of the contact angle and dynamic viscosity of aqueous solutions influenced by surfactants. To aqueous solutions were added the most common anionic, nonionic and cationic surfactants. The optimal concentrations of anionic, nonionic and cationic surfactants in the «icy» water. It is established that at the optimal concentration of surfactant surface tension value is minimum. For these concentration surfactant were chosen and the value for dynamic coefficient of viscosity. We calculated average thickness of the laminar boundary layer when added to water, the optimal concentration of the studied surfactants. It is established that the reduction of surface tension minimizes the thickness of laminar boundary layers in the wall of the pipe-water. It is shown that the average speed in the near-wall layers for adding optimum concentrations of the studied surfactants. increases, and as a result this system is able to effectively transfer heat. Defined numerical ranges of the surface criterion for «ice» water with the addition of various surfactants. It is established that the value surface of the criterion of $P_{o}$ depend on the surface tension of the coolant. It was experimentally confirmed that when optimal concentrations of surfactant, there is a minimum value surface of the criterion of $P_{o}$. From the graph based on superficial criteria from concentrations of surfactant, it is possible to determine the surface criterion and speed in $L B L$.

Key words: laminar boundary layer, average thickness of boundary laminar layer, surface tension, surfactans, speed in a laminar boundary layer, optimal concentrations, superficial criterion.

\section{Вступ}

Основною проблемою переробних галузей промисловості є низька їх енергоефективність. Не винятком $€$ і підприємства харчової промисловості. Рідкофазні харчові продукти, молоко, соки, пиво, вершки та ін. повинні піддаватися тепловій обробці - пастеризації, охолодженню, оскільки швидко псуються, а тому i значні енерговитрати відбуваються саме на стадії теплової обробки продуктів. Всі ці процеси протікають у спеціальних теплообмінних апаратах, тобто на межі контакту двох фаз тверде тіло-рідина (стінка теплообмінника-теплоносій). На межі розділу двох фаз рідина - стінка трубопроводу виникає потужне поле сил поверхневого натягу, що змінює потік рідини 3 утворенням ламінарного приграничного шару (ЛПШ).

Існування ЛПШ шару розглядають 3 позиції гідромеханіки, тобто з врахуванням тангенціальних напружень від сили тертя в ЛПШ шарі (Kuk, 1973). Нова наукова концепція розгляду гідромеханічних процесів, руху рідини в трубопроводах та апаратах з врахуванням дії сил поверхневого натягу на границі контакту тверде тіло-рідина була запропонована в роботі (Bilonoha, 2006). В роботі (Bilonoha, 2006) був розглянутий елементарний об'єм рідини в трубопроводі в межах ЛПШ та проаналізовано сили, що діють на цей об’єм і враховуючи теорію подібності, були одержані такі критеріі:

$$
\begin{aligned}
& P_{0}=\frac{1}{N} \frac{2 \pi \sigma \cos \theta}{\mu v_{x}}-\text { поверхневий критерій в ЛПШ } \\
& N=\frac{v_{x} \delta \rho}{\mu}=10,47-11,5
\end{aligned}
$$

де N - видозмінений критерій Рейнольдса, (Kuk, 1973)

$$
\begin{aligned}
& E u=\frac{p}{\rho v_{x}^{2}}-\text { критерій Ейлера в ЛПШ } \\
& F r=\frac{g \delta}{v_{x}^{2}}-\text { критерій Фруда в ЛПШ } \\
& \frac{1}{\operatorname{Re}}=\frac{\mu}{\delta \rho v_{x}}-\text { обернений критерій Рейнольда в }
\end{aligned}
$$$$
\text { ЛПШ }
$$

Також було встановлено їх числове значення. Поверхневий критерій для води за нормальних умов $P_{0}=376,81$, критерій Ейлера $E u=100$, критерій Фруда $F r=0,071$, обернений критерій Рейнольда $\frac{1}{\mathrm{Re}}=0,033$ (Bilonoha, 2006). Оскільки числові значення поверхневого критерію $P_{0}$ та критерію Ейлера $E u$ в ЛПШ на декілька порядків є більші від критерію Фруда та 
оберненого критерію Рейнольдса, то останніми можна знехтувати.

Мета роботи: знайти діапазон поверхневого критерію для «льодяної» води за додавання оптимальних концентрацій різного виду ПАР.

\section{Результати та їх обговорення}

3 рівності (1) видно, що значення поверхневого числа суттєво залежать від коефіцієнта поверхневого натягу, швидкості в пристінних шарах $v_{x}$ та видозміненого крітерію Рейнольдса N. Відомо, що коефіцієнт поверхневого натягу рідкофазних теплоносіїв можна зменшувати шляхом додавання до них малих концентрацій поверхнево-активних речовин (ПАР). Для ви- значення діапазону значень поверхневого критерію проведена серія експериментів по забезпеченню зміни коефіцієнта поверхневого натягу $\sigma$, косинуса кута змочування $\cos \theta$ та динамічного коефіцієнта в'язкості $\mu$ водних розчинів під впливом ПАР. До водних розчинів додавались найбільш поширені аніонна, неіонна та катіонна ПАР. Коефіцієнт поверхневого натягу, динамічний коефіцієнт в'язкості та косинус кута змочування теплоносія визначали за загальновідомими методиками (Adamson, 1976).

На рис. 1 показані залежності коефіцієнта поверхневого натягу, динамічного коефіцієнта в'язкості води та косинуса кута змочуваннявід концентрації аніоної, неіонної та катіонної ПАР.

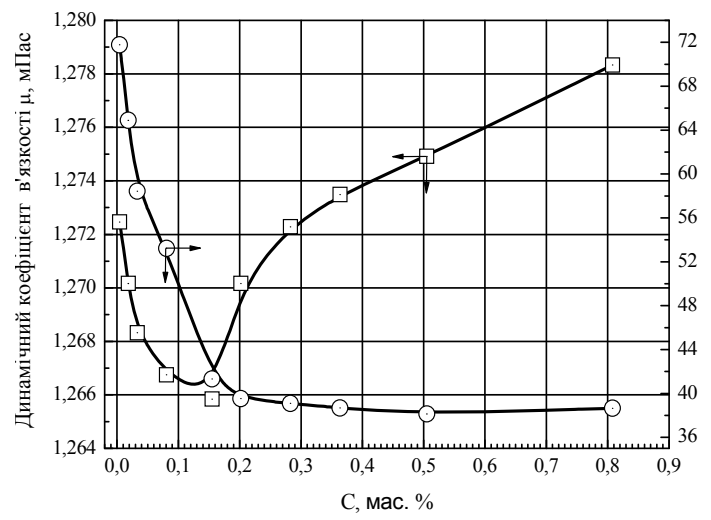

a)

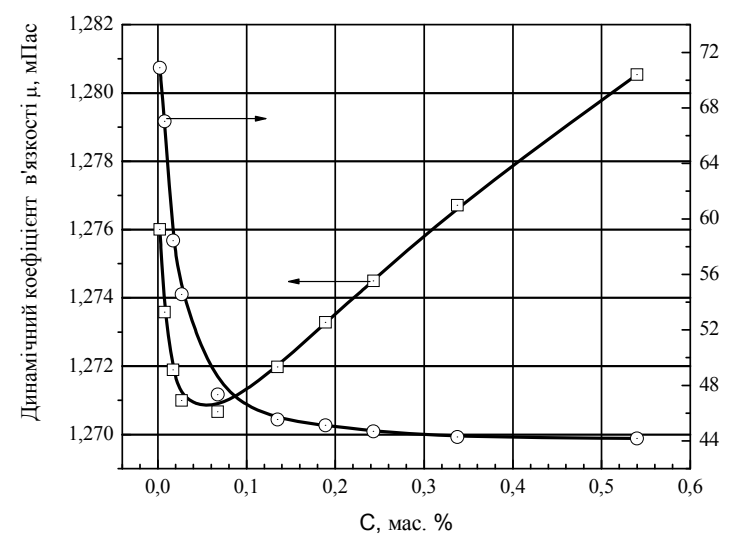

B)

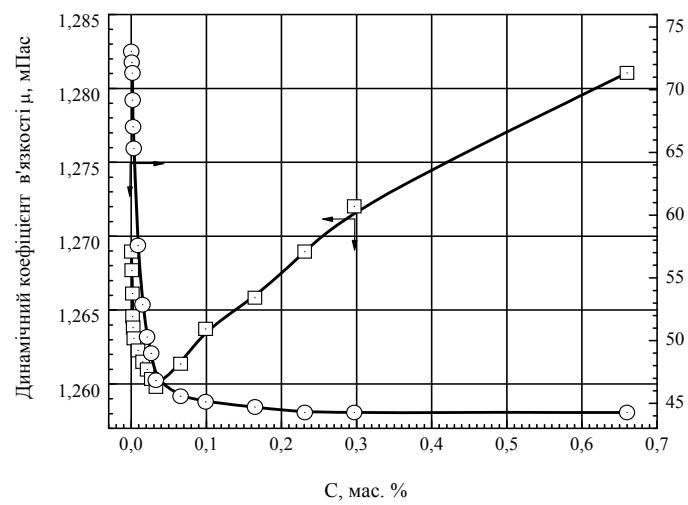

б)

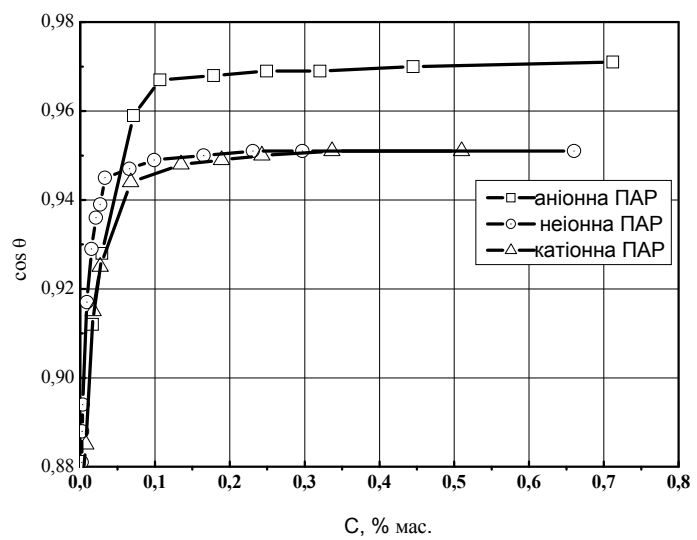

г) ізотерма змочування для водних розчинів досліджуваних ПАР

Рис. 1. Залежність коефіціснта поверхневого натягу $\sigma$, динамічного коефіціснта в'язкості $\mu$ та косинуса кута соsө змочування води від концентрації досліджуваних ПАР: а) аніонної; б) неіонної, в) катіонної ПАР, г) ізотерма змочування

Як видно з графіків, на кривій залежності коефіцієнта поверхневого натягу від концентрації є мінімуми, які відповідають критичній концентрації міцелоутворення (ККМ). Тобто за незначного зростання концентрацій ПАР коефіцієнт поверхневого натягу різко зменшується до ККМ, а за концентрацій вище ККМ спостерігається незначне його зменшення.

Для аніонної ПАР ККМ спостерігається за концентрації $(0,10 \ldots 0,15)$ мас.\%. За цієї концентрації коефіцієнт поверхневого натягу води зменшується в 1,98 рази, для неіонної за концентрації $(0,05 \ldots 0,10)$ мас.\% - в 1,66 рази, а для катіонної за концентрації $(0,08 \ldots 0,15)$ мас.\%. - в 1,57 рази в порівнянні з водою. Ці концентрації вважаються оптимальними. За цих концентрацій ПАР вибирали і значення для динамічного коефіцієнта в'язкості. Рідина з меншим значенням коефіцієнта поверхневого натягу краще змочує поверхню твердого тіла, при цьому кут змочування стає більш гострішим. На рис. 1 (г) показано зале- 
жність косинуса кута змочування води від концентрації ПАР.

Покажемо зміну поверхневого числа $P_{o}$ в ЛПШ для водних розчинів за додавання оптимальних концентрацій досліджених ПАР. Швидкість в пристінних шарах знаходили $з$ видозміненого числа Рейнольдса $v_{x}=\frac{N \mu}{\delta \rho}$, приймаючи значення $\mathrm{N}=10,5$, а середню товщину ЛПШ знаходили за формулою: $\delta=\frac{\frac{d^{2}}{\operatorname{Re} \mu} \sqrt{\frac{2 \sigma \cos \theta \rho}{\lambda l}}}{K_{T}}$, де $\sigma-$ коефіцієнт поверхневого натягу, Н/м; $\cos \theta$ - гідрофільність поверхні стінки;

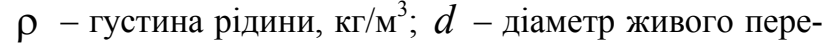
piзу потоку, м; $\lambda-$ коефіцієнт Дарсі; $\lambda=\frac{0,316}{\mathrm{Re}^{0,25}}$;

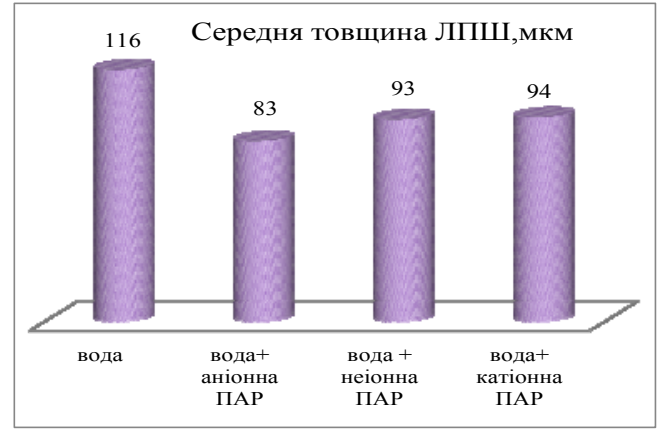

a) $l$ - довжина трубопроводу, м; $\mu$ - коефіцієнт динамічної в'язкості рідини, Па с; $K_{T}$ - коефіцієнт турбулізації Л шару, $K_{T}=\frac{\operatorname{Re}_{p о б}}{\operatorname{Re}_{\kappa p}} ; \operatorname{Re}_{\kappa p} \approx 2320$. Число Рейнольдса $\mathrm{Re}_{\text {роб }}$ знаходили за формулою $\mathrm{Re}=\frac{v d \rho}{\mu}$.

На підприємствах харчової, фармацевтичної та переробної промисловостей середня швидкість руху рідин в теплообмінній апаратурі становить $v \approx 1 \mathrm{~m} / \mathrm{c}$, діаметр труб $d=21 \cdot 10^{-3} \mathrm{M}$, довжина труб $l=3 \mathrm{м}$.

Значення середньої товщини ЛПШ для «льодяної» води (рис. 2а) та середню швидкість в ЛПШ (рис. 2б) за додавання оптимальних концентрацій досліджуваних ПАР показано на рис. 2.

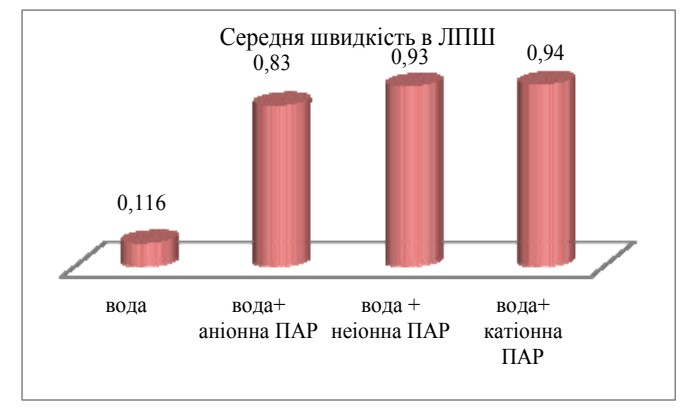

б)

Рис.2. а) значення середньої товщини ЛПШ б) значення середньої швидкість в ЛПШ за додавання ПАР

Отже, середні товщини ЛПШ під дією ПАР зменшились. За додавання аніонної ПАР в 1,4 рази; за додавання неіонної ПАР - у 1,25 рази, за додавання катіонної ПАР - у 1,23 рази. Додавання оптимальних концентрацій різних ПАР до води (теплоносія) можна суттєво зменшити коефіцієнт поверхневого натягу, мінімізувавши середню товщину ЛПШ в системі стінка трубопроводу - теплоносій. Середню швидкість ЛПШ під впливом вказаних ПАР розраховували за формулою (2). Значення середньої швидкості ЛПШ для різних видів ПАР представлено на рис. 2 б.

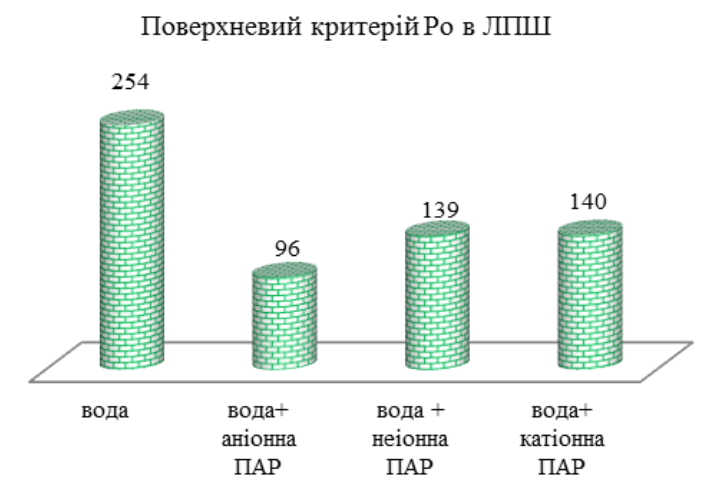

Рис. 3. Значення поверхневого критерію $P_{0}$ в ЛПШ для різних ПАР
Зменшуючи середні товщини ЛПШ води, швидкість в них зростає, а це інтенсифікує проходження кількості теплоти через нього. Також енергія зв'язку між стінкою трубопроводу і приповерхневим шаром води зменшується, мінімізується «прилипання» рідини до стінок. Оскільки середня товщина ЛПШ суттєво залежить від коефіцієнта поверхневого натягу рідини, то і швидкість в приповерхневих шарах також залежить від нього.

Значення поверхневого числа розраховані згідно формули (1) представлені на рис. 3.

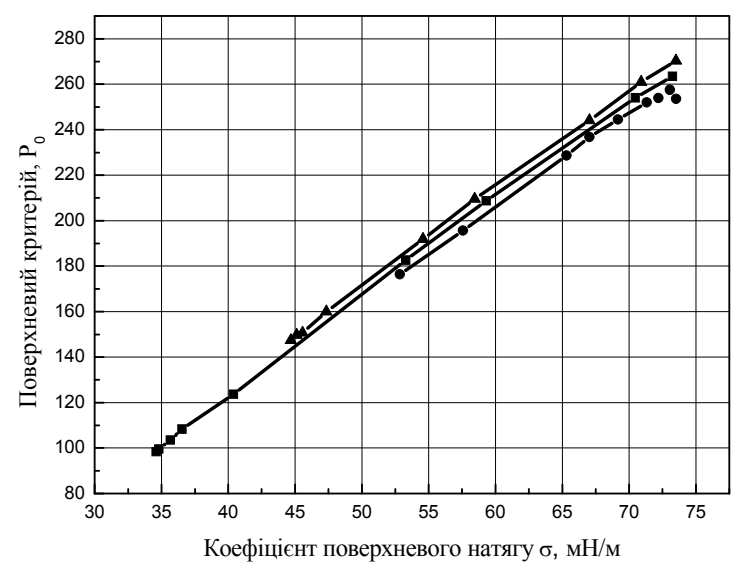

Рис. 4. Залежність поверхневого критерію від концентрацій ПАР 
Поверхневий критерій є функцією від коефіцієнта поверхневого натягу теплоносія. При зменшенні коефіцієнта поверхневого натягу теплоносія значення поверхневого критерію $P_{0}$ також зменшуються. На рис. 4. показано залежність поверхневого критерію від концентрацій досліджуваних ПАР у воді.

Оскільки всі значення поверхневого критерію $P_{0}$ лежать на прямій і накладаються, то з такої залежності, вимірявши коефіцієнт поверхневого натягу $\sigma$ після введення ПАР у теплоносій, можна визначити поверхневий критерій та швидкість у ЛПШ

$$
v_{x}=\frac{2 \pi \sigma \cos \theta}{\mu N P_{0}}
$$

Отже, за додавання оптимальних концентрацій ПАР до води, суттєво зменшується коефіцієнт поверхневого натягу, середня товщина ЛПШ $є$ мінімальною, а середня швидкість в цьому шарі $\epsilon$ максимальною, і значення поверхневого критерію - мінімальне, що дозволяє інтенсифікувати проходження кількості тепла за таких умов.

\section{Висновки}

1. Встановлено, що сили поверхневого натягу в межах ЛПШ характеризуються величиною поверхневого критерію $P_{0}$.
2. Для характеристики теплоносія та можливості інтенсифікації теплопередачі запропоновано новий безрозмірний комплекс - поверхневий критерій $P_{0}$, що $\epsilon$ функцією від коефіцієнта поверхневого натягу теплоносія.

3. Встановлено діапазон поверхневого критерію для водних розчинів ПАР (96-140).

\section{Бібліографічні посилання}

Kuk, G.A. (1973). Processy i apparaty molochnoj promyshlennosti. M. : Pishhevaja promyshlennost' (in Russian).

Bilonoha, Yu.L. (2006). Intensyfikatsiia ta optymizatsiia teplomasoobminnykh protsesiv pry vyrobnytstvi orhanopreparativ i pererobtsi vtorynnoi syrovyny miasokombinativ: avtoreferat dys....doktora tekhn. nauk: 05.18.12. Odesa, 36 (in Ukrainian).

Bilonoha, Yu.L. (2006). Pro dotsilnist rozghliadu hidromekhanichnykh protsesiv $\mathrm{z}$ vrakhuvanniam syl poverkhnevoho natiahu na hranytsi kontaktu tverde tilo-ridyna. Intehrovani tekhnolohii ta enerhozberezhennia. 2, 64 (in Ukrainian).

Adamson, A. (1976). Fizicheskaja himija poverhnostej: per. s ang. M.: Mir (in Russian).

Стаття надійшла до редакиії 1.03.2017 